\title{
Comentarios a la tradición palmista "El baile de la Victoria"
}

\author{
Eduardo Arroyo Laguna \\ Universidad Ricardo Palma \\ eduardoarroyo29@gmail.com
}

\section{Resumen}

El presente artículo analiza la tradición palmista "El baile de la Victoria", considerado como el baile más fastuoso de la historia republicana, llevado a cabo en el año de 1853 durante el gobierno del general Rufino Echenique.

Palabras clave: baile, historia republicana, Rufino Echenique, Ricardo Palma.

\section{Abstract}

This essay analyzes the palmist tradition "Victoria's dance", which is considered as the most pompous party of our republican history, realized in 1853, during Rufino Echenique's presidency.

Keywords: Dance, republican history, Rufino Echenique, Ricardo Palma. 
Eduardo Arroyo Laguna, sociólogo, poeta, ensayista, periodista, promotor cultural.

Doctor en Ciencia Política y Relaciones Internacionales. por la Universidad Ricardo Palma, Magíster en Sociología por la Pontificia Universidad Católica del Perú y Licenciado en Sociología por la Universidad Mayor de San Marcos. Lima-Perú. Es docente en la Universidad Ricardo Palma desde 1974, Asesor del Rectorado y encargado de la coordinación con las embajadas y misiones diplomáticas acreditadas en el Perú. Enseña también en la Maestría en Sociología de la Universidad Nacional Mayor de San Marcos y en la Facultad de Ciencias Sociales de la Universidad Nacional Federico Villarreal. Es autor de libros de sociología, narrativa y poemarios, y colaborador periodístico de los diarios El Comercio, La República y Diario Uno. 
La historia peruana ha sido marcada desde muy antiguo por el espíritu trabajador de sus habitantes en el marco de una estructura colectivista en torno a la tierra, la que, sin tener una gran dotación de agua ni grandes extensiones de territorios buenos para el cultivo, logró construir un imperio agrario. El trabajo feliz, alegre, fraterno sobre la pachamama caracterizó a nuestros antepasados. La invasión europea significó una ruptura de cataclismo con nuestra historia y ordenamiento social.

Nuestro pueblo estaba dedicado en cuerpo y alma al arduo trabajo colectivo sobre la tierra. A su derrota se sumó el carácter rentista y mercantilista de la Colonia. En aquel entonces, la tenencia de oro y plata aseguraba el predominio en la escena internacional, lo que llevó a que España viviera enfrentada a Francia e Inglaterra, combatiendo en los océanos su hegemonía en el sistema mercantil de aquel entonces. Mientras los reinos de la península ibérica ofrecían al mundo un sistema que reposaba en torno a la explotación minera, los otros países europeos ya habían iniciado su proceso de acumulación originaria del capital y su incipiente capitalismo las presentaba como naciones más modernas.

España trae a nuestros territorios un espíritu feudal que reposó en la explotación minera, teniendo la suerte de encontrar vastos yacimientos de oro y plata. Necesitado de estos minerales para asegurar su dominación mundial, se explica que haya practicado un genocidio sobre nuestro imperio, que de tener quince millones de habitantes pasó en el tiempo a tener escasos cincuenta mil moradores indígenas. En la mita se consumó el exterminio sobre los nuestros.

El ocio y la urgencia rentista son parte de la herencia ibérica, el saqueo de los minerales y la tierra para asegurar esa dominación. Sobre ese trajín se irguió lo que Palma llama boato, esplendor. "Facer la América" se convirtió entonces en un destino, una actitud, la aventura de la vida, y a estas tierras exóticas vinieron 
a cambiar de status social, a lograr ganancias y enriquecerse, ganados por las leyendas que se difundían sobre nuestros territorios. Si algunos se perdieron buscando el oropel y la gloria en la Amazonía, otros empobrecidos invasores pasaron a ser lo que no fueron en su madre patria. Aquí advinieron en encomenderos con indios y tierras a su cargo, algo que no hubieran logrado en la península ibérica.

Hubieron de dividir racialmente el país en un Perú de españoles blancos y extranjeros (considerado superior) versus un Perú de indios, casi de seres semihumanos (considerado inferior). En la base de los peruanos acomplejados de la hora actual, está el no haberse quitado en cinco siglos la astilla despectiva de desprecio hacia lo nuestro.

Toda su vocación patrimonialista, de considerar que sus territorios eran su patrimonio en donde podían hacer y deshacer, se extiende a aquellos que hacen de las arcas del Estado su propiedad. Lo rentista, lo hereditario, lo mercantilista, el depender de los frutos de la tierra, aprovechándola sin industrializarla, son actitudes que no vienen de nuestro ancestro prehispánico sino que revelan la herencia colonial. Es estamental y, por tanto, sigue pensando en pleno siglo XXI en castas, clases sociales, apellidos y razas no sustentadas en el mérito o en el esfuerzo sino en la herencia, en el sello de sangre, sin el menor aprecio por el trabajo, que al final es la real huella que deja la gente digna y decente.

Toda la obra de don Ricardo Palma Soriano es una confrontación con el orden colonial instaurado en el Perú, así como también con el sistema republicano, en un autor hábil en hallar las diferencias y hacer sorna del contrincante.

No es -y creo que los miembros del Instituto Ricardo Palma convendremos en ello- que Palma sea un particular defensor de 
los derechos de los reinos de Castilla y Aragón. No lo ha sido ni de hecho ni de palabra ni de pluma. Palma es un contestatario. Por su origen, extracción de clase dirían los sociólogos, como el que escribe estas líneas, Palma es hijo de una cuarterona y de un mestizo, habiendo recibido en este país de acomplejados y frustrados motes sobre su negritud, a los que el tradicionista responderá ponderadamente con la muletilla: "Quien no tiene de inga, tiene de mandinga".

Además, contra toda farisea pureza de razas y etnias, al momento de la invasión europea sobre nuestras comarcas, lo que se llamaba España era más bien una exageración lexicológica, ya que constituía una confederación de reinos enfrentados unos con otros. Fue bajo la hegemonía de Castilla, con Pizarro, Almagro y Luque, que llegaron a nuestros territorios y sometieron a nuestra población. Ya los peruleros habían pasado antes por Centro América y el Caribe.

No resolvieron en su momento su unión estructural, si bien enfrentaron unidos la invasión árabe, triunfo que lograron tras ocho siglos de dominación que los marcó genética y culturalmente. Conviene recordar que el mundo árabe se adelantó a numerosos inventos del mundo grecolatino, en órdenes como la aritmética, el álgebra, la trigonometría y en cuanto a léxico y numerosos descubrimientos, todos ellos de origen moro.

Los godos o chapetones, como llama Palma a los hijos de la península ibérica, son también denominados peninsulares o "peruleros", como adjetiva José Antonio del Busto Duthurburu a los invasores, que no conquistadores. Una invasión es coger un territorio ajeno y quitar soberanía físico-territorial así como cultural a sus habitantes; mientras que la conquista es un término que denota ganar por la fuerza un territorio sin necesariamente quitar sus creencias, léxico y autoridades a los sometidos. 
España era una entelequia, como puede serlo ahora que los independentistas de Cataluña nos hacen ver las ansias de autonomía de estas regiones. No habiendo resuelto en su raíz los problemas estructurales de su cohesión, estos reaparecen con el tiempo. Nada menos que el núcleo industrial de España quiere su autonomía frente a una España recesada y con alto índice de desempleo.

\section{Los actores sociales coloniales se suceden en la República}

El invasor europeo, queriendo demostrar ante el mundo su poderío, hizo reposar tal esplendor en la tenencia de oro y plata obtenida en esta colonia. Sin nuestros territorios no hubieran asegurado su dominación mundial. Nos deben su nombradía en esos siglos hasta que nos independizamos y caemos bajo la férula de Inglaterra, Francia y luego Estados Unidos, países que lograrán su poderío siempre valiéndose de algún recurso natural que existía en demasía en nuestros territorios.

Palma critica el boato basado en ese episodio de extracción de oro y plata a nivel mundial. Se trata de una aristocracia virreinal que buscaba diferenciarse de las demás en sus signos exteriores de riqueza. El boom del oro y la plata les daban el pretexto y la base material. De ahí que esta aristocracia virreinal, que viviera estos siglos de opulencia, dejará ese imaginario de riqueza y esplendor en sus textos, en las imágenes de historiadores, geógrafos y antropólogos.

Son un Perú y una Lima narcisistas, que se miran al espejo y caen, cual Narciso, enamorados de ellos mismos. Lima vivió estos episodios y no es con la República con la que cambian estructuralmente las cosas. La vida republicana peruana inicia su existencia con prácticamente los mismos actores sociales. Nos dice 
Palma en su tradición "El baile de la Victoria" que "Nada había cambiado. Sólo faltaba el virrey, y créanme ustedes que la mayoría del vecindario limeño lo echaba de menos" (1964: 1124).

O sea que la gesta independentista no fue un hecho de masas populares radicalizadas, sino liderado por una pequeña burguesía criolla que, tras la Independencia, no advino en una burguesía que lanzara al país a un proyecto nacional que entusiasmara al conjunto de clases y etnias y que anunciara el nuevo desarrollo nacional. Esta fue la primera revolución independentista que, liberándose del yugo feudal español, no se convirtió en capitalista porque nuestras clases medias criollas carecieron del élan empresarial para relanzar el país por esos derroteros. Así se marcaron las indecisiones del país, indecisiones que tenemos hasta el momento actual.

Por ello es que acercándonos al bicentenario de la independencia criolla, debemos recordar que un proyecto independentista integral mayor fue el de Túpac Amaru en 1780, y que aún arrastramos las consecuencias de la dominación de la civilización europea implantada a sangre y fuego, prevaleciendo la exclusión social, las desigualdades sociales, las brechas de género-clase, etnia, ideología, como el racismo y el choleo, creyéndose que así se blanquea el choleador.

Nuestros triunfos episódicos en el fútbol indican en la actualidad el desborde de una nueva peruanidad, un Perú mestizo en donde la selección peruana de fútbol es la mejor expresión del Perú real, un Perú cholo, centralmente mestizo. La gente se siente representada en este seleccionado como no se ha sentido hasta ahora.

\section{El baile de la Victoria}

Nos dice Palma, que naciera en 1833, es decir, una década después de los hechos de la independencia criolla, que: 
No con el último disparo de fusil en el camino de Ayacucho desapareció la vida colonial. En cuanto a costumbres, se siguió, en toda casa de buen gobierno, almorzando de nueve a diez de la mañana, comiendo de tres a cuatro de la tarde, cenando a las diez de la noche, rezando el rosario en familia antes de meterse entre palomares (vulgo sábanas)... (Ibid.: 1124).

Ya en otra de sus tradiciones, "Con días y ollas venceremos", Palma sostiene que él mismo en su niñez disfrutaba de las costumbres que la Lima republicana había heredado de la Lima colonial, los mismos usos y los mismos actores sociales. Nos habla de una Lima de "abajo el puente", Lima al nivel del río Rímac, la Lima plebeya que llega a vender sus productos a la Lima aristocrática, por encima del ras del río, y en una Lima sin relojes que eran las que daba la hora.

Juzgue el lector por el siguiente cuadrito de cómo distribuían las horas en mi barrio, allá cuando yo andaba haciendo novillos por huertas y murallas, y muy distante de escribir tradiciones y dragonear de poeta, que es otra forma de matar el tiempo o de hacer novillos (Ibid.: 960).

El tradicionista da testimonio de cómo se sucedían desde las seis de la mañana hasta las diez de la noche la lechera, la tisanera y la chichera; el bizcochero y la vendedora de leche-vinagre; la vendedora de zanguito, de ñajú y choncholíes; la tamalera y la melonera; la vendedora de ranfañote, cocada, bocado de rey, chancaquitas de cancha y de maní y frejoles colados; el frutero de canasta; el vendedor de ante con ante, la arrocera y el alfajorero; la picaronera, el humitero y el de la rica causa de Trujillo; a las tres de la tarde el melcochero, la turronera y el anticuchero; la picantera y el de la piñita de nuez; el jazminero, el de las caramanducas y el vendedor de flores de trapo; el raicero y el galletero; el caramelero, la mazamorrera y la champucera; el heladero y el barquillero; a las nueve de la noche el animero 
o sacristán de la parroquia; y a las diez, el sereno del barrio. Palma confiesa con nostalgia que “...para saber con fijeza la hora en que uno vivía, ningún reloj más puntual que el pregón de los vendedores..." (Ibid.: 960).

Pues este país y esta capital, tras la Independencia, no cambió mucho, siguiendo las mismas costumbres y sobre todo con los mismos actores sociales recreando el viejo espíritu patrimonial aristocrático, sus estamentos, su carácter rentista y demás desigualdades sociales. Sólo faltaba el virrey y muchos lo extrañaban.

La propia ley independentista había abolido los títulos que llegaron de Castilla, pero en las calles la gente seguía su rutina de denominar y saludar a los marqueses y a los condes. Nos dice Palma:

Ciertamente que la aristocracia de los pergaminos, con las leves excepciones de toda regla, no descollaba por el talento o la ilustración, pero sí deslumbraba todavía por su riqueza y boato.... Nada abundaba tanto en Lima como los hombres buenos que no sirven para nada (Ibid.: 1125).

Alberto Flores Galindo sostiene que la corte virreinal competía en cuanto a la cantidad de esclavos mostrada, los caballos y carruajes, las armas de cacería; y en el caso de las mujeres, los vestidos y alhajas (1984: 73-81). La aristocracia limeña desarrolló rasgos endogámicos y vivió en el lujo.

\section{De la opulencia virreinal a la opulencia republicana}

Es conocido que el boom guanero dio la base material para el enriquecimiento de una primera clase empresarial nacional, a falta de una clase social burguesa que dirigiera el proceso libertario peruano de la Independencia. Estos primeros 
consignatarios del guano se asociaron al gran capital británico en calidad de socios menores, lograron su porcentaje de ganancia y lejos de reinvertir sus capitales en el Perú, los sacaron hacia el extranjero. Carecieron, pues, de alma nacional y mal puede llamárselos burguesía nacional. En honor a la verdad, nuestra gesta independentista criolla no fue una revolución democrática burguesa que lanzara el país al capitalismo, quedándose entre feudal y capitalista. Son los rasgos que históricamente se reproducirán en nuestras clases dominantes.

A la vieja aristocracia colonial, que se mantuvo en la República, la de la ley del valor plata sucedió una nueva aristocracia de cuño republicano, la del valor de oro, en donde se priorizaba el oro por encima de la plata. Son dos aristocracias las que se encuentran en este crecimiento del país y de Lima como epicentro de la modernidad de un país que advenía a la era republicana.

No descollaba esta aristocracia, nos dice Palma, por su talento sino centralmente por su riqueza y boato. Todos estos aristócratas profesaban un culto al vil metal, al metal sellado y carecían del espíritu capitalista de riesgo, no participando en aventuras especulativas ni invirtiendo en nada grandilocuente. De allí que guardaran su capital muchas veces debajo del colchón, por lo que Palma concluyera diciendo que Lima estaba poblada de gente buena, contemplativa de su dinero y carente de la fibra capitalista para la aventura empresarial moderna.

La tradición "El baile de la Victoria" nos muestra a estos actores sociales en una fiesta que tuvo lugar en la "Quinta Victoria", llamada así por doña Victoria Tristán de Echenique, prima hermana de Flora Tristán y esposa del entonces presidente de la República y general Rufino Echenique. Además, nos permite conocer detalles singulares de la historia del actual distrito de La Victoria, a algunas leguas del centro de Lima, pasadas las 
murallas que rodeaban la ciudad capital. Conviene recordar que este es un baile que se lleva a cabo el 15 de octubre de 1853 y que las murallas de Lima recién se demolerán entre 1868 y 1872. Al tumbarse estos parapetos, La Victoria fue el primer distrito en extenderse urbanísticamente, siendo fundado el 2 de febrero de 1920 durante el segundo gobierno de Augusto B. Leguía.

Resulta paradójico que el presidente Echenique, al darse cuenta del dispendio que generaban las competencias entre el patrón plata y el patrón oro, y preocupado porque el país se iba a un abismo sin fondo, buscara que el Congreso diera una ley que impidiera y pusiera fin al derroche, lo que pidió ante Cámaras en 1853. Buscando halagar a los congresistas, organizó esta fiesta.

$\mathrm{Al}$ respecto, hay diversas versiones. Palma menciona en su tradición que efectivamente avanzado el proceso de la Consolidación se iba a estos disparates. La propia República había creado esta nueva aristocracia ya que desde el gobierno de Castilla se había decidido.

LA CONSOLIDACIÓN. En el capítulo concerniente a la política hacendaria durante el primer gobierno de Castilla se vio cómo las leyes de setiembre y diciembre de 1847, marzo de 1848 y marzo de 1850 autorizaron el reconocimiento y la cancelación de los créditos de los particulares contra el Estado hasta 1845... El propio Echenique aseveró en su mensaje al Congreso extraordinario de 1853 que, cuando se hizo cargo del Estado, encontró reconocida la cantidad de 5'237,242 pesos, casi toda procedente de ajustes y descuentos insolutos... El propio Echenique, en su mensaje del 28 de julio de 1853 y a través de premiosas gestiones personales pidió al Parlamento que diese por definitivamente cerrada la consolidación... (Basadre, 1964: 1011-1035). 
El propio Palma recoge en esta tradición que el presidente Echenique, buscando cerrar el capítulo de la Consolidación con un pedido hecho al Parlamento y para apoyar el voto de los congresistas, llevó a cabo este baile, al cual invitó a toda la clase dirigente ramificada en el aparato estatal. Indudablemente que todos coinciden, incluyendo Palma, en que esta fiesta fue la más grande de la época republicana, superando las realizadas en la Colonia y que llevó posteriormente a una guerra civil, a partir de las críticas al dispendio mostrado.

Palma fue testigo de excepción de este baile ya que fue invitado como marino que era, con solo 19 años de edad, y nos dice que supera a dos célebres bailes anteriores: el que diera Ramoncita, la hija del virrey Abascal, y el que ofreciera a la sociedad limeña doña Ángela Cevallos, la esposa del virrey Pezuela (Op. Cit.: 1126).

Lo paradójico es que se hace un baile sumamente ostentoso para evitar el dispendio que se cernía sobre el país, producto de la convivencia del patrón plata con el patrón oro. Preocupaba a Echenique que la Consolidación llevase al país a la quiebra, al pagar las deudas del Estado para con los particulares creando una nueva clase y aristocracia y un nuevo patrón, el de oro que pasaba a convivir con el colonial patrón de plata; y para dar fin a tanto derroche, se organiza una fiesta que es recordada en la historia de nuestra sociedad como la más fastuosa de todos los tiempos. Se busca curar con el dispendio la lucha contra el dispendio. El mundo al revés.

Este baile fue parte del derroche nacional en estos años de boom guanero, de descentralización anarquista del país en que don Ramón Castilla luchaba por recentralizar un Perú que se disgregaba por "quítame estas pajas".

Se habló de gastos por sesenta mil pesos solo para reparar el edificio, alfombras de Flandes, aparatos de iluminación a gas 
en una Lima que carecía de ese tipo de alumbrado, mobiliario, comida y demás gastos. A esta fiesta acudieron ministros de Estado, el cuerpo diplomático, vocales de la Corte Suprema y otras autoridades y personalidades de la sociedad limeña, que en total configuraban mil caballeros y 239 señoras y señoritas. En los espaciosos salones resaltaban pinturas originales de Velásquez, Murillo y el "Españoleto", así como del pintor nacional Ignacio Merino, quien había sido recientemente premiado en París. En cuanto a la abundancia de flores que decoraban las puertas, paredes y corredores de la finca, se dijo que se agotaron las de todos los jardines de Lima.

Animaron el baile las cantantes de la compañía de ópera italiana Clotilde Barilli y Elisa Biscaccianti. La orquesta de Teatro estuvo dirigida por el maestro César Lietti y cuando los músicos tenían necesidad de reposo eran reemplazados por las bandas militares de la Artillería y del batallón Granaderos.

Quizá lo más espectacular de aquella velada fue la exhibición de alhajas. Las señoras de la antigua aristocracia colonial no dejaron nada en el cofre de la familia y portaron joyas de plata. Pero las damas de la reciente oligarquía del guano, las "nuevas ricas" de la época, las eclipsaron por el lujo de sus vestidos y por lo vistoso de sus alhajas engarzadas en oro. Como dama de alcurnia, hija del denominado último virrey don Pío Tristán, la anfitriona doña Victoria lució con serena altivez solamente alhajas engarzadas en plata.

A la una de la madrugada hubo media hora de reposo en el baile. Pocos bailarines monopolizaban a una pareja, todos bailaban con todos. A las tres de la madrugada empezó la cena para doscientos cuarenta cubiertos, renovándose el servicio tres veces más. Con el amanecer se bailó el cotillón, que puso término a este fastuoso baile. 
El baño o toilette para las señoras abundaba en buen gusto y refinamientos orientales. Tenía, además, puerta de comunicación con otra salita donde la costurera, madame Dubreuil, con 6 asistentas, atendía arreglando, a fuerza de puntadas, todo desperfecto ocasionado en las faldas por bailarines poco diestros.

El diario El Comercio, en su edición del lunes 17 de octubre de 1853, elogia este baile y don José Arnaldo Márquez la incluye en la lista de actos dispendiosos y de corrupción forjados en el Perú por nuestras clases dominantes. Sostendrá que Palma, quien no sabía bailar, se dedicó con sus amigos a la conversación, que era una actividad que le causaba mucho placer.

Tanta resonancia tuvo este baile en todo el país que, como consecuencia de él, se desató, según afirma Palma, la guerra civil, debido al derroche y exceso de lujo mostrado, que aparecía como un insulto a la pobreza general del país. Castilla se levantó en armas y venció finalmente al general Echenique en la batalla de La Palma, en enero de 1855, en los alrededores de la huaca Pucllana.

Por ello es que el ilustre tradicionista nos dice en esta tradición fechada en 1853, bajo el gobierno presidencial de Echenique, que Lima conservaba aún los rasgos coloniales. Su concurrencia formaba parte de las más altas esferas del poder económico y la aristocracia, la cual se dividía en la aristocracia antigua venida a menos y la aristocracia del dinero, emergiendo esta última de la Consolidación Republicana. De hecho, los pagos que el Estado hizo a particulares tras la Independencia sacaron a muchos de la pobreza y los catapultó a una opulencia soberbia. Es una clase social hija de la llamada Consolidación.

Culmino esta ponencia con un texto de don Jorge Basadre:

... que en él las damas de las antiguas familias coloniales lucieron las viejas joyas de plata; en cambio, las que habían 
comprado sus joyas recientemente sólo podían exhibir las que tenían engaste de oro, únicas que eran vendidas en las tiendas de Lima. En este detalle aparentemente frívolo se ve el tránsito de una nueva clase social a las más altas posiciones, compitiendo con la nobleza genealógica un grupo de enriquecidos durante la República, gracias al guano. No era, sin embargo, la primera vez que en el Perú ocurría el fenómeno de ascensión social debida a la fortuna; enriquecidos fueron también los conquistadores del siglo XVI y los que, durante el siglo XVIII, compraron sus títulos de nobleza. Pero en estos casos los recién llegados a la cumbre de la vida social se acomodaron a un estilo de vida aristocrático; ahora la antigua clase alta debía adaptarse a una sociedad donde el dinero empezaba a dominar (Basadre, 1964: 1063).

\section{Bibliografía}

Palma, R. (1964). El baile de la Victoria (Reminiscencias). En: Tradiciones Peruanas Completas. Madrid: Ediciones Aguilar, quinta edición; edición y prólogo de Edith Palma, nieta del autor con siete extensos apéndices y una selección de cartas del autor. Edición autorizada por las hijas del autor.

Basadre, J. (1964). Historia de la República del Perú, tomo III. Lima: Editorial Peruamérica, quinta edición aumentada y corregida, segunda reimpresión.

Flores Galindo, A. (1984). Aristocracia y plebe. Lima, 1760-1830. Lima: Mosca Azul editores, primera edición.

Márquez, J. A. (1888). La orgía financiera del Perú.

Recibido el 4 de diciembre del 2017 Aprobado el 18 de enero del 2018 